\title{
Peer-Pressure and Rational Underage Binge-Drinking
}

\author{
Amnon Levy \\ School of Economics, University of Wollongong, Wollongong, Australia \\ Email: Amnon_levy@uow.edu.au
}

Received December 10, 2013; revised January 10, 2014; accepted January 17, 2014

Copyright (C 2014 Amnon Levy. This is an open access article distributed under the Creative Commons Attribution License, which permits unrestricted use, distribution, and reproduction in any medium, provided the original work is properly cited. In accordance of the Creative Commons Attribution License all Copyrights (C) 2014 are reserved for SCIRP and the owner of the intellectual property Amnon Levy. All Copyright (C) 2014 are guarded by law and by SCIRP as a guardian.

\begin{abstract}
This paper provides a utility-based definition of binge-drinking and examines the compatibility of this phenomenon with a rational decision making. Prohibition of young people's consumption of alcohol is frequently violated by binge-drinking in groups. The analysis considers the roles of peer-pressure, full price of alcohol and crowding in underage group-drinking sessions and identifies the conditions for binge-drinking by expected utility maximizing members. Rational binge-drinking occurs when the impact of the peer-pressure on the individual member's utility exceeds the loss of utility from the forgone spending on all other goods associated with the expected full marginal cost of consuming alcohol.
\end{abstract}

\section{KEYWORDS}

\section{Minimum Age; Peer Pressure; Rationality; Binge-Drinking}

\section{Introduction}

The optimal level of public investment in controlling the prevalence of use of intoxicating substances is linked to the choice between prohibition and accommodation. Prohibition of alcohol had been decreed in several western countries during the early part of the twentieth century, most notably the United States. It can be argued that, in view of the large initial proportion of regular alcohol consumers, prohibition has not been a socially optimal policy. In an earlier study (Levy et al. [1]), the co-authors and I have stressed the non-concavity of the Hamiltonian associated with the public planner's optimal control problem in the number of users as giving rise to unstable steady states and to a certain number of users that is critical for determining the socioeconomically optimal control trajectory. Namely, only if the initial number of users is smaller than the critical number associated with the Dechert-Nishimura-Skiba point, a trajectory supported by a strong early control effort that ensures embarking on a path of elimination of the use of the intoxicating substance under consideration is socially optimal. However, if the initial users' number exceeds that critical number, the full costs of elimination are too high and a lower early public control effort that ensures embarking on the stable manifold to the saddle point steady state with a large number of users is optimal.

Prohibition has become socially undesirable as bootlegging and organised crime took control of the supply of alcohol. Consequently, it was replaced by accommodation, but with a minimum-age restriction. As juveniles mature in different pace, there is not a physiologically uniform optimal minimum age of drinking. Aged-based prohibition has been applied with a significant variation of the minimum age across countries: as low as sixteen in several European countries and as high as twenty-one in the United States. Despite the implementation of minimum age restrictions on alcohol consumption, bingedrinking by groups of young people has been a prevalent phenomenon and a major cause for accidents, aggression and, consequently, injuries and fatalities (cf. CASAC [2] and Courtney and Polich [3]). There have been claims that lowering the relatively high minimum legal age of drinking in the United States can reduce alcohol consumption and its harms. Carpenter and Dobkin [4] have found that the available data do not support those claims.

Restrictions encourage formation of groups that facilitate their violation. The focus of this theoretical paper is on the possible link between underage binge-drinking and participation in a group-drinking session. The paper 
considers aspects of affiliation to a group of alcohol consumers that are relevant to the investigation of whether binge-drinking can be an outcome of a decision making that is oriented to maximize the individual members' expected utility. A confirmation may reflect the difficulty in controlling the prevalence of alcohol abuse and its harms. In other words, if binge-drinking can be prevalent within a group of expected utility maximizing underage consumers, it can be expected to be more intensive within a group of underage alcohol consumers who evaluate the expected benefits and costs of drinking in a less rational manner.

On the one hand, affiliation to a drinking group moderates the personal price of alcohol for the underage individual members. In addition to the acquisition cost, the personal price of alcohol includes the moral costs of breaking the law and the costs of risk-bearing stemming from possible involvement in accidents and violent exchange. Naturally, the larger the group, the greater is its bargaining power as well as its ability to provide moral support, care and protection to members. That is, the size of the group lowers the personal price of alcohol and, ceteris paribus, increases the quantity of alcohol demanded by the members.

Yet, as demonstrated in the ensuing sections, the moderating effect of group on personal price cannot by itself prove binge-drinking to be rational in the said von Neumann-Morgenstern sense. The individual member's level of alcohol consumption might be further intensified by peers' expectations of displaying good-drinking companionship. The paper demonstrates the crucial role of the individual utility's sensitivity to such peer pressure in rendering binge-drinking as a possible rational choice.

On the other hand, an income effect should be taken into account. Due to intoxication there can be a negative relationship between earning and alcohol consumption. In addition, crowding increases the probability of being noticed by law-enforcers and, consequently, fined.

To set the stage for the analysis of the group's overall effect on rational members' consumption of alcohol, Sections 2 and 3 consider the case of solitary drinkers (i.e., individuals whose utility is not affected by externalities that could have been generated by shared-drinking sessions) in a society free of age restrictions on alcohol consumption. In particular, Section 2 offers a formulation of the utility from alcohol and, subsequently, a utility-based definition of binge drinking and Section 3 provides a relationship between earnings and consumption of alcohol and, consequently, the budget for all other goods. These preliminary formulation and analysis lead to the conclusion that, at any age, binge-drinking is not optimal for a lone rational drinker.

Section 4 formulates the effects of minimum-age restriction and participating in underage group-drinking sessions on members' expected utilities and, subse- quently, identifies the conditions for rational bingedrinking. Section 5 concludes.

\section{Utility-Based Definition of Binge-Drinking}

To provide a utility-based definition of binge-drinking let us consider a setting where the individual's utility from consuming alcohol is not tainted by external effects; namely, drinking in solitary. The formulation of the utility from consuming alcohol in solitary at any given age is based on the following assumptions. A week is the relevant unit of time as it is neither too short, nor too long, for recording the individual's cycle of drinking, work, study and consumption of other goods and services. The individual's weekly cycle commences with drinking in a private session that starts, say, on Saturday night and finishes by early Sunday morning. During the rest of the week the individual refrains from consuming alcohol (due to work, care and/or study duties). By the next Saturday night the individual is fully recovered from the adverse effects of alcohol.

The individual's alcohol consumption in the weekly session at $t$ years of age $\left(c_{t}\right)$ has an age-dependent tolerance upper-bound $\left(\bar{c}_{t}\right)$, which indicates her/his incapacitating intake at that particular age. Reaching this tolerance upper-bound nullifies the individual's productivity and, in turn, income and spending on goods services during the following seven days. The consumption of alcohol might also directly decrease the individual's utility from some goods and services and increase the utility from others. As the aggregate direct effect is not clear, and for simplicity, overall neutrality is assumed and displayed by separability between the utility from alcohol and the utility from all other goods and services. That is, at any age $t$, the individual's (overall) weekly utility $\left(u_{t}\right)$ is equal to the sum of the weekly utility from alcohol $\left(u_{t}^{a}\right)$ and the weekly utility from all other goods and services $\left(u_{t}^{g}\right)$ :

$$
u_{t}=u_{t}^{a}+u_{t}^{g} \text {. }
$$

The weekly utility from alcohol is taken to be equal to the difference between the pleasure from drinking and the discomfort associated with intoxication (loss of muscle coordination, drowsiness, nausea, etc.). At sufficiently low levels of consumption, the t-year old individual's marginal pleasure from drinking exceeds the marginal discomfort. But while the marginal pleasure diminishes with the consumed quantity of alcohol, the marginal discomfort is increasing and eventually becomes dominant. At a certain consumption level, $\hat{c}_{t}$, within the physiologically feasible range $\left(0, \bar{c}_{t}\right)$ the marginal discomfort is equal to the marginal pleasure, rendering the marginal weekly utility from alcohol to be zero. This property can be captured by the following analytically convenient specification: 


$$
u_{t}^{a}=\alpha_{t} c_{t}-\beta_{t} c_{t}^{2}
$$

where the age-dependent coefficients are such that $\alpha_{t}>\beta_{t}>0$. This specification can be viewed as a second-order approximation of a general, single-peaked, function of weekly utility from alcohol:

$$
u_{t}^{a}\left(c_{t}\right) \simeq u_{t}^{a}(0)+u_{t}^{a^{\prime}}(0) c_{t}+0.5 u_{t}^{a^{\prime \prime}}(0) c_{t}^{2}
$$

with $u_{t}^{a}(0)=0, \alpha=u_{t}^{a^{\prime}}(0)>0$ and

$-\beta=0.5 u_{t}^{a^{\prime \prime}}(0)<0$. As $u_{t}^{a^{\prime}}\left(\hat{c}_{t}\right)=0, \hat{c}_{t}=\alpha_{t} / 2 \beta_{t}$ and, consequently, $\beta_{t}=0.5 \alpha_{t} / \hat{c}_{t}$. In turn, Equation (2) can be expressed as:

$$
u_{t}^{a}=\alpha_{t}\left[c_{t}-0.5\left(c_{t}^{2} / \hat{c}_{t}\right)\right] .
$$

Since $u_{t}^{a^{\prime}} \gtrless 0$ as $c_{t} \lessgtr \hat{c}_{t}$, then (from the perspective of generating weekly utility from alcohol per se) $\hat{c}_{t}$ is the individual's bliss intake of alcohol in a weekly drinking session at $t$-years of age. Consumption of alcohol beyond $\hat{c}_{t}$ is excessive and represents binge-drinking. In contrast to the rule of thumb that regards consumption beyond four shots, in the case of females, and five shots, in the case of males, as binge-drinking (Courtney and Polich [3]), this proposed definition is sensitive to individual variations. The intensity of bingedrinking can be measured by $\left[\left(c_{t}-\hat{c}_{t}\right) /\left(\bar{c}_{t}-\hat{c}_{t}\right)\right] \in(0,1)$ for any $c_{t} \in\left(\hat{c}_{t}, \bar{c}_{t}\right)$.

\section{Income Effect and Solitary Consumption of Alcohol in the Absence of Age Restrictions}

The consumption of alcohol reduces productivity and, consequently, the budget available for buying goods. Let us take all other goods as an aggregate, $p>0$ the relative price of alcohol and $I_{t}$ the individual's weekly income, or performance-based allowance given by parents in the case of non-working adolescents. For simplicity, the individual's marginal weekly utility from spending on all other goods $\left(I_{t}-p c_{t}\right)$ is taken to be constant, but can be age dependent $\left(\gamma_{t}>0\right)$. The individual's current weekly income is assumed to decline from an alcohol-free age-dependent level, $I_{t}^{f}$, proportionally to the individual's degree of incapacitation by alcohol, i.e., $I_{t}=\left(1-c_{t} / \bar{c}_{t}\right) I_{t}^{f}$. Hence, the individual weekly utility from all the other (non-alcoholic) goods is:

$$
u_{t}^{g}=\gamma_{t}\left[\left(1-c_{t} / \bar{c}_{t}\right) I_{t}^{f}-p c_{t}\right] \text {. }
$$

Recalling Equations (1), (3) and (4), the weekly utility of a solitary consumer of alcohol is:

$$
u_{t}=\alpha_{t}\left[c_{t}-0.5\left(c_{t}^{2} / \hat{c}_{t}\right)\right]+\gamma_{t}\left[\left(1-c_{t} / \bar{c}_{t}\right) I_{t}^{f}-p c_{t}\right] \text {. }
$$

A rational $t$-year old solitary person sets $c_{t}$ to maximize her/his weekly utility. The first-order condition for maximum weekly utility is:

$$
u_{t}^{\prime}=\alpha_{t}-\alpha_{t} \frac{c_{t}^{*}}{\hat{c}_{t}}-\gamma_{t}\left[p+\left(1 / \bar{c}_{t}\right) I_{t}^{f}\right]=0 .
$$

As the second-order condition is satisfied $\left(-\alpha / \hat{c}_{t}<0\right)$, the optimal weekly alcohol consumption in solitary for a $t$-year old person is

$$
c_{t}^{*}=\left[1-\frac{\gamma_{t}}{\alpha_{t}}\left(p+\frac{I_{t}^{f}}{\bar{c}_{t}}\right)\right] \hat{c}_{t} .
$$

Proposition 1. A rational person who drinks alone does not binge.

Proof: From Equation (7), $c_{t}^{*} \leq \hat{c}_{t}$ as $p+I_{t}^{f} / \bar{c}_{t} \geq 0$.

At any age, the individual's utility maximizing consumption of alcohol in solitary is lower than her/his current age bliss intake by a proportion that is equal to the product of the full price of alcohol $\left[p+\left(I_{t}^{f} / \bar{c}_{t}\right)\right]$ and the relative marginal utility from all other goods $\left(\gamma_{t} / \alpha_{t}\right)$. Even when alcohol is freely available, a rational person drinks in solitary less than $\hat{c}_{t}$ as long as drinking has an adverse effect on her/his earning ability.

\section{Minimum-Age Restriction, Group Influence and Alcohol Consumption}

The analysis presented in the previous section suggests that rational people do not binge-drink in solitary. It is demonstrated in this section that this outcome does not necessarily prevail when they face a binding minimumage restriction and, as frequently observed, drink in groups. The present section incorporates the effects of minimum-age restriction and groups into the formulation of the expected utility function of underage consumers of alcohol and identifies the conditions for rational underage people to binge-drink.

As in the previous section, a weekly cycle is considered with a drinking session that starts on Saturday night and finishes on early Sunday morning and, therefore, affects the participants during the following seven days. But now the drinking session is shared with similarly under-aged companions and the participants are facing a risk of being noticed by law-enforcers and, subsequently, punished.

In addition to the direct satisfaction from consuming alcohol, a person who participates in a group-drinking session can gain (loose) utility from increased (diminished) reputation of being an invaluable drinking companion proportionally to the product of the deviation of her/his alcohol consumption from an expected minimum norm, $c_{t}^{e}>0$, and the relative size of the group of the rest the drinking-session's members:

$$
R_{t}=r_{t}\left(\left(n_{t}-1\right) / \bar{n}_{t}\right)\left(c_{t}-c_{t}^{e}\right)
$$

where $r_{t} \geq 0$ is an age-dependent coefficient, $\bar{n}_{t}$ is the largest possible group of affiliation for the underage under consideration, and $n_{t}$ is a predetermined number of 
the drinking-session's members. In this specification, $n_{t}-1$ indicates the number of drinkers accompanying the individual under consideration, $0 \leq\left(n_{t}-1\right) / \bar{n}_{t}<1$ indicates the intensity of peer pressure and $r_{t}$ the sensitivity of the individual's weekly utility to peer pressure.

There are other disadvantages and advantages from drinking in group. On the one hand, the probability of being noticed by law enforcers and, in turn, punished, increases with crowding-namely, the number of companions. With $0<\varphi_{t}<1$ denoting the probability of being noticed by law-enforcers for the largest possible group of $t$-year old underage drinkers, the probability of being noticed for a $t$-year old underage drinker in a group of $n_{t} \leq \bar{n}_{t}$ is $\varphi_{t}\left(n_{t} / \bar{n}_{t}\right)$. Since similarity to eligible-age consumers increases with age, it is possible that $\varphi_{t}$ diminishes as $t$ converges to the minimum age. The punishment for drinking is assumed to be a fine that is pro- portional to the level of alcohol consumption: $\mu_{t} c_{t}$, where $\mu_{t} \geq 0$ is an age-dependent fine per unit of alcohol. The underage alcohol consumer expects a portion $0 \leq \varepsilon_{t} \leq 1$ of the fine to be borne by her/his parents, depending on their degree of leniency.

On the other hand, affiliation to a group reduces the personal price of alcohol for the underage individual consumer. The larger the group, the greater are its bargaining, supportive, caring and protecting capabilities. We assume that the personal price of alcohol for a group member is $\left[1-\theta_{t}\left(n_{t} / \bar{n}_{t}\right)\right] p_{t}^{s}$, where $p_{t}^{s}$ is the personal price of alcohol for alone $t$-year old person facing age restrictions and $0<\theta_{t}<1$. Due to limited access to alcohol, $p_{t}^{s}>p$. Yet, it is possible that $p_{t}^{s}$ decreases and $\theta_{t}$ increases with $t$.

In view of these assumptions and Equation (5), the distribution of the underage consumer's weekly utility is:

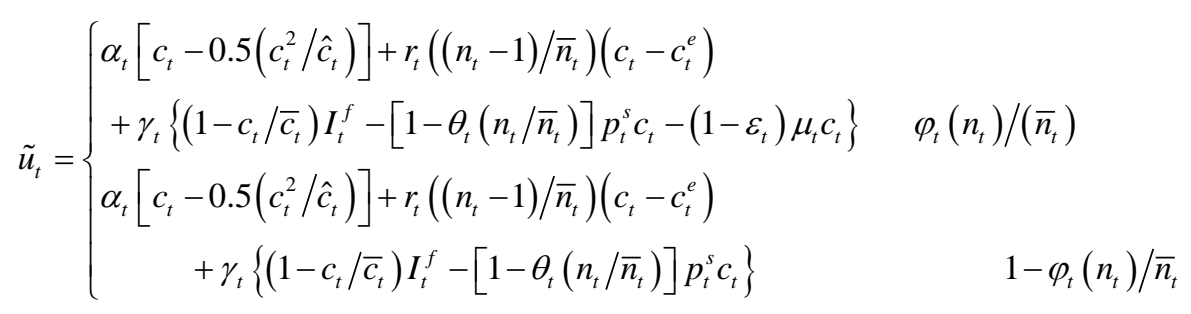

and her/his expected weekly utility is:

$$
\begin{aligned}
E\left(\tilde{u}_{t}\right)= & \alpha_{t}\left[c_{t}-0.5\left(c_{t}^{2} / \hat{c}_{t}\right)\right]+r_{t}\left(\left(n_{t}-1\right) / \bar{n}_{t}\right)\left(c_{t}-c_{t}^{e}\right) \\
& +\gamma_{t}\left\{\left(1-c_{t} / \bar{c}_{t}\right) I_{t}^{f}-\left[1-\theta_{t}\left(n_{t} / \bar{n}_{t}\right)\right] p_{t}^{s} c_{t}\right\}-\varphi_{t}\left(n_{t} / \bar{n}_{t}\right) \gamma_{t}\left(1-\varepsilon_{t}\right) \mu_{t} c_{t}
\end{aligned} .
$$

A rational, in the von Neumann-Morgenstern sense, underage person chooses an alcohol intake in the weekly groupdrinking session that maximizes her/his expected weekly utility. As $E\left(\tilde{u}_{t}\right)$ is concave in $c_{t}$, that underage's optimal alcohol consumption must satisfy the following necessary condition:

$$
\alpha_{t}\left[1-\left(c_{t}^{o} / \hat{c}_{t}\right)\right]+r_{t}\left(\left(n_{t}-1\right) / \bar{n}_{t}\right)-\left(\gamma_{t} / \bar{c}_{t}\right) I_{t}^{f}-\gamma_{t}\left[1-\theta_{t}\left(n_{t} / \bar{n}_{t}\right)\right] p_{t}^{s}-\varphi_{t}\left(n_{t} / \bar{n}_{t}\right)\left(1-\varepsilon_{t}\right) \mu_{t}=0 .
$$

Consequently,

$$
c_{t}^{o}=\left[1+\frac{\left[r_{t}\left(n_{t}-1\right) / \bar{n}_{t}+\gamma_{t} \theta_{t} p_{t}^{s}-\varphi_{t} \gamma_{t}\left(1-\varepsilon_{t}\right) \mu_{t}\right]\left(n_{t} / \bar{n}_{t}\right)-\gamma_{t}\left[p_{t}^{s}+\left(I_{t}^{f} / \bar{c}_{t}\right)\right]}{\alpha_{t}}\right] \hat{c}_{t} .
$$

As indicated earlier, the size of the drinking group is taken to be exogenous: namely, the underage person under consideration neither has the power to form her/his own group, nor the opportunity to select one from a set of groups with variable size. Of course, a rational person joins an existing group of $n_{t}-1>0$ veteran members, or quit her group of $n_{t}>1$ members, if, and only if, $E\left(\tilde{u}_{t}\left(c_{t}^{o}\left(n_{t}>1\right)\right)\right)-E\left(\tilde{u}_{t}\left(c_{t}^{o}\left(n_{t}=1\right)\right)\right)$ is larger, or smaller, than zero, respectively. As shown in the Appendix,

$$
\begin{aligned}
E & \left(\tilde{u}_{t}\left(c_{t}^{o}\left(n_{t}>1\right)\right)\right)-E\left(\tilde{u}_{t}\left(c_{t}^{o}\left(n_{t}=1\right)\right)\right) \\
= & r_{t}\left[\left(n_{t}-1\right) / \bar{n}_{t}\right]\left[c_{t}^{o}\left(n_{t}>1\right)-c_{t}^{e}\right]+\left(\left[\alpha_{t}-\gamma_{t} I_{t}^{f} / \bar{c}_{t}\right]\left\{\left[r_{t}\left(n_{t}-1\right) / \bar{n}_{t}-\varphi_{t} \gamma_{t}\left(1-\varepsilon_{t}\right) \mu_{t}\right]\left(\left(n_{t}-1\right) / \bar{n}_{t}\right)\right\} / \alpha_{t}\right) \hat{c}_{t} \\
& -\gamma_{t}\left\{\left[1-\theta_{t}\left(n_{t} / \bar{n}_{t}\right)\right] p_{t}^{s}+\varphi_{t}\left(n_{t} / \bar{n}_{t}\right)\left(1-\varepsilon_{t}\right) \mu_{t}\right\} c_{t}^{o}\left(n_{t}>1\right)+\gamma_{t}\left\{\left[1-\theta_{t}\left(1 / \bar{n}_{t}\right)\right] p_{t}^{s}+\varphi_{t}\left(1 / \bar{n}_{t}\right)\left(1-\varepsilon_{t}\right) \mu_{t}\right\} c_{t}^{o}\left(n_{t}=1\right) \\
& -\left(0.5 \alpha_{t} / \hat{c}_{t}\right)\left[c_{t}^{o}\left(n_{t}>1\right)^{2}-c_{t}^{o}\left(n_{t}=1\right)^{2}\right]
\end{aligned}
$$


where $c_{t}^{o}\left(n_{t}>1\right)$ is given by Equation (12) and

$$
c_{t}^{o}(n=1)=\left[1+\frac{\left[\gamma_{t} \theta_{t} p_{t}^{s}-\varphi_{t} \gamma_{t}\left(1-\varepsilon_{t}\right) \mu_{t}\right]\left(1 / \bar{n}_{t}\right)-\gamma_{t}\left[p_{t}^{s}+\left(I_{t}^{f} / \bar{c}_{t}\right)\right]}{\alpha_{t}}\right] \hat{c}_{t} .
$$

\section{Proposition 2.}

1) If $r_{t}$ is greater (smaller) than $\gamma_{t}\left[\varphi_{t}\left(1-\varepsilon_{t}\right) \mu_{t}-\theta_{t} p_{t}^{s}\right]$, then a rational underage person consumes a larger (smaller) quantity of alcohol in group-drinking sessions than in seclusion. (Straightforward from comparing the right-hand side of Equation (12) when $n_{t}>1$ to that when $\left.n_{t}=1\right)$.

2) If $r_{t}\left(\left(n_{t}-1\right) / \bar{n}_{t}\right)>\gamma_{t}\left\{\varphi_{t}\left(n_{t} / \bar{t}_{t}\right)\left(1-\varepsilon_{t}\right) \mu_{t}+\left[\left(1-\theta_{t}\left(n_{t} / \bar{t}_{t}\right)\right) p_{t}^{s}+\left(I_{t}^{f} / \bar{c}_{t}\right)\right]\right\}$, then a rational underage person binge-drinks in group-drinking sessions (Straightforward from Equation (12)).

\section{Conclusions}

Rational binge-drinking presents a strong cognitive obstacle to overcome alcoholism. The paper considers aspects of affiliation to a group of alcohol consumers that are relevant to the investigation of whether binge-drinking can be an outcome of an individual member's decision making that is oriented to maximize her/his expected utility. The first part of Proposition 2 reveals that switching from solitary drinking to drinking in company does not necessarily increase the alcohol consumption of a rational underage person. Her/his alcohol consumption can be reduced by participating in group-drinking sessions if the sensitivity of her/his utility to peer pressure is smaller than the difference between the forgone utility from spending on other goods associated with the intensifying marginal effect of crowding on the expected selffinanced fine and the utility gains from spending on other goods associated with the moderating marginal effect of the group's bargaining power on the price of alcohol.

The second part of Proposition 2 says that, unlike rational consumption of alcohol in solitary, rational consumption of alcohol in company can exceed the personal bliss level. As $0<\theta_{t}<1$ and $0<n_{t} / \bar{n}_{t} \leq 1$,

$$
\varphi_{t}\left(n_{t} / \bar{n}_{t}\right)\left(1-\varepsilon_{t}\right) \mu_{t}+\left\{\left[1-\theta_{t}\left(n_{t} / \bar{n}_{t}\right)\right] p_{t}^{s}+\left(I_{t}^{f} / \bar{c}_{t}\right)\right\}>0 .
$$

That is, the moderating effect of the bargaining power of the group cannot by itself lead rational members of a drinking session to binge-drink. Rational binge-drinking occurs when the impact of the peer-pressure on the individual's weekly utility exceeds the loss of utility from the forgone spending on all other goods associated with the expected full marginal cost of alcohol which, in addition to the full price in the absence of age restrictions, includes the self-financed portion of the marginal expected fine. Peer-pressure, compounded by sensitivity of the individual's weekly utility to such a pressure, and sufficiently low marginal utility from spending on all other goods are essential for underage binge-drinking to be rational. The critical sensitivity $\left(r_{t}\right)$ to peer pressure required for a rational binge-drinking to take place decreases with the expected portion of the fine to be borne by the parents $\left(\varepsilon_{t}\right)$, the moderating effect of the group's bargaining power on the purchasing price of alcohol $\left(\theta_{t}\right)$ and the individual's tolerance to alcohol $\left(\bar{c}_{t}\right)$, and increases with the probability of being noticed by lawenforcers $\left(\varphi_{t}\left(n_{t} / \bar{n}_{t}\right)\right)$, the ratio of the fine to the intake of alcohol $\left(\mu_{t}\right)$, the alcohol-free (potential) weekly earning $\left(I_{t}^{f}\right)$, and the marginal weekly utility from all other goods $\left(\gamma_{t}\right)$.

There may be a positive relationship between sensitivity to peer pressure and age during adolescence. The underlying rationale is that being initially responsive to parents' and/or educators' expectations, adolescents may become more and more sensitive to friends' expectations at the passage of years. The existence of such a relationship can be manifested by a greater prevalence of binge drinking within older cohorts of adolescents.

\section{REFERENCES}

[1] A. Levy, F. Neri and D. Grass, "Macroeconomic Aspects of Substance Abuse: Diffusion, Productivity and Optimal Control," Macroeconomic Dynamics, Vol. 10, No. 2, 2006, pp. 145-164. http://dx.doi.org/10.1017/S1365100506050140

[2] CASAC, “Teen Tipplers: America’s Underage Drinking Epidemic,” National Center on Addiction and Substance Abuse at Columbia University, New York, 2002.

[3] K. E. Courtney and J. Polich, "Binge Drinking in Young Adults: Data, Definitions, and Determinants," Psychological Bulletin, Vol. 135, No. 1, 2009, pp. 142-156. http://dx.doi.org/10.1037/a0014414

[4] C. Carpenter and C. Dobkin, "The Minimum Legal Drinking Age and Public Health," Journal of Economic Perspectives, Vol. 25, No. 2, 2011, pp. 133-156. http://dx.doi.org/10.1257/jep.25.2.133 


\section{Appendix}

From Equation (10),

$$
\begin{aligned}
& E\left(\tilde{u}_{t}\left(c_{t}^{o}\left(n_{t}>1\right)\right)\right)=\left[\gamma_{t} I_{t}^{f}-r_{t}\left(\left(n_{t}-1\right) / \bar{n}_{t}\right) c_{t}^{e}\right]+\left\{\alpha_{t}+r_{t}\left(\left(n_{t}-1\right) / \bar{n}_{t}\right)-\gamma_{t} I_{t}^{f} / \bar{c}_{t}-\gamma_{t}\left[1-\theta_{t}\left(n_{t} / \bar{n}_{t}\right)\right] p_{t}^{s}\right. \\
& \left.-\gamma_{t} \varphi_{t}\left(n_{t} / \bar{n}_{t}\right)\left(1-\varepsilon_{t}\right) \mu_{t}\right\} c_{n}^{o}-\left(0.5 \alpha_{t} / \hat{c}_{t}\right) c_{n}^{o 2}
\end{aligned}
$$

and

$$
E\left(\tilde{u}_{t}\left(c_{t}^{o}\left(n_{t}=1\right)\right)\right)=\gamma_{t} I_{t}^{f}+\left\{\alpha_{t}-I_{t}^{f} / \bar{c}_{t}-\gamma_{t}\left[1-\theta_{t}\left(1 / \bar{n}_{t}\right)\right] p_{t}^{s}-\gamma_{t} \varphi_{t}\left(1 / \bar{n}_{t}\right)\left(1-\varepsilon_{t}\right) \mu_{t}\right\} c_{1}^{o}-\left(0.5 \alpha_{t} / \hat{c}_{t}\right) c_{1}^{o 2} .
$$

Hence,

$E\left(\tilde{u}_{t}\left(c_{t}^{o}\left(n_{t}>1\right)\right)\right)-E\left(\tilde{u}_{t}\left(c_{t}^{o}\left(n_{t}=1\right)\right)\right)=-r_{t}\left(\left(n_{t}-1\right) / \bar{n}_{t}\right) c_{t}^{e}+\left\{\alpha_{t}+r_{t}\left(\left(n_{t}-1\right) / \bar{n}_{t}\right)-\gamma_{t} I_{t}^{f} / \bar{c}_{t}-\gamma_{t}\left[1-\theta_{t}\left(n_{t} / \bar{n}_{t}\right)\right] p_{t}^{s}\right.$ $\left.-\gamma_{t} \varphi_{t}\left(n_{t} / \bar{n}_{t}\right)\left(1-\varepsilon_{t}\right) \mu_{t}\right\} c_{n}^{o}-\left\{\alpha_{t}-\gamma_{t} I_{t}^{f} / \bar{c}_{t}-\gamma_{t}\left[1-\theta_{t}\left(1 / \bar{n}_{t}\right)\right] p_{t}^{s}-\gamma_{t} \varphi_{t}\left(1 / \bar{n}_{t}\right)\left(1-\varepsilon_{t}\right) \mu_{t}\right\} c_{1}^{o}-\left(0.5 \alpha_{t} / \hat{c}_{t}\right)\left[c_{n}^{o 2}-c_{1}^{o 2}\right]$

By collecting terms,

$\left.E\left(\tilde{u}_{t}\left(c_{t}^{o}\left(n_{t}>1\right)\right)\right)-E\left(\tilde{u}_{t}\left(c_{t}^{o}\left(n_{t}=1\right)\right)\right)=r_{t}\left[\left(n_{t}-1\right) / \bar{n}_{t}\right)\right]\left(c_{n}^{o}-c_{t}^{e}\right)+\left[\alpha_{t}-\gamma_{t} I_{t}^{f} / \bar{c}_{t}\right]\left(c_{n}^{o}-c_{1}^{o}\right)-\gamma_{t}\left\{\left[1-\theta_{t}\left(n_{t} / \bar{n}_{t}\right)\right] p_{t}^{s}\right.$ $\left.+\varphi_{t}\left(n_{t} / \bar{n}_{t}\right)\left(1-\varepsilon_{t}\right) \mu_{t}\right\} c_{n}^{o}+\gamma_{t}\left\{\left[1-\theta_{t}\left(1 / \bar{n}_{t}\right)\right] p_{t}^{s}+\varphi_{t}\left(1 / \bar{n}_{t}\right)\left(1-\varepsilon_{t}\right) \mu_{t}\right\} c_{1}^{o}-\left(0.5 \alpha_{t} / \hat{c}_{t}\right)\left[c_{n}^{o 2}-c_{1}^{o 2}\right]$

From Equation (12),

$$
c_{t}^{o}\left(n_{t}>1\right)=\left[1+\frac{\left[r_{t}\left(n_{t}-1\right) / \bar{n}_{t}+\gamma_{t} \theta_{t} p_{t}^{s}-\varphi_{t} \gamma_{t}\left(1-\varepsilon_{t}\right) \mu_{t}\right]\left(n_{t} / \bar{n}_{t}\right)-\gamma_{t}\left[p_{t}^{s}+\left(I_{t}^{f} / \bar{c}_{t}\right)\right]}{\alpha_{t}}\right] \hat{c}_{t}
$$

and

$$
c_{t}^{o}(n=1)=\left[1+\frac{\left[\gamma_{t} \theta_{t} p_{t}^{s}-\varphi_{t} \gamma_{t}\left(1-\varepsilon_{t}\right) \mu_{t}\right]\left(1 / \bar{n}_{t}\right)-\gamma_{t}\left[p_{t}^{s}+\left(I_{t}^{f} / \bar{c}_{t}\right)\right]}{\alpha_{t}}\right] \hat{c}_{t} .
$$

Hence,

$$
c_{t}^{o}\left(n_{t}>1\right)-c_{t}^{o}(n=1)=\left[\frac{\left[r_{t}\left(n_{t}-1\right) / \bar{n}_{t}-\varphi_{t} \gamma_{t}\left(1-\varepsilon_{t}\right) \mu_{t}\right]\left(\left(n_{t}-1\right) / \bar{n}_{t}\right)}{\alpha_{t}}\right] \hat{c}_{t} .
$$

